\title{
In Vitro Stability and Recovery Studies of Pimavanserin in Water and in Different Vehicles Orally Administered
}

\author{
Allan David Bokser ${ }^{1}\left[\right.$ [ $\cdot$ Yvonne Holmes Adegbenle ${ }^{1} \cdot$ Vesna Stoisavljevic $^{2} \cdot$ James C. Norton $^{1}$
}

Accepted: 29 December 2021 / Published online: 2 February 2022

(c) The Author(s) 2022

\begin{abstract}
Background and objective Swallowing difficulties (i.e., dysphagia) occur in up to $40 \%$ of the adult general population, particularly among the elderly prescribed solid oral dosage forms. Pimavanserin is approved for the treatment of hallucinations and delusions in patients with Parkinson's disease psychosis (PDP) as a 34-mg capsule formulation. Patients with PDP may be at-risk for dysphagia that could affect administration of intact pimavanserin capsules. The stability of oral pimavanserin was evaluated in different liquid/soft food vehicles.

Methods The stability of pimavanserin intended for oral administration was assessed by sprinkling the contents of 1 pimavanserin 34-mg capsule into water $(40 \mathrm{~mL})$, applesauce $(40 \mathrm{~g})$, vanilla Ensure $(60 \mathrm{~mL})$, or non-pulp orange juice $(60 \mathrm{~mL})$. Results The stability study demonstrated $>95 \%$ recovery within 24 hours after contents of a 34-mg pimavanserin capsule were dispersed in applesauce, vanilla Ensure ${ }^{\circledR}$, orange juice, or water. Assay values at $24 \mathrm{~h}$ for individual capsules were within 5\% of time zero, and no significant change in the impurity profile was observed in any vehicle. Pimavanserin degradation products recovered from various food vehicles for individual and total degradation products were $<0.5 \%$ at all time points. In addition, the impurity profile of compatibility samples matched that obtained for a control sample.

Conclusion These results support the ability of pimavanserin to be given orally by emptying the capsule contents into soft foods or liquids in accordance with the product label.
\end{abstract}

\section{Key Points}

In vitro studies were undertaken with pimavanserin to evaluate its stability and recovery when administered orally in different liquid/soft food vehicles and in water.

Pimavanserin can be administered by emptying the capsule contents into applesauce, orange juice, vanilla Ensure $^{\circledR}$, or water and delivering orally.

Pimavanserin offers the flexibility to be administered using alternative vehicles to accommodate patient needs.
Allan David Bokser

abokser@ACADIA-pharm.com

1 ACADIA Pharmaceuticals, Inc., 12830 El Camino Real, Suite 400, San Diego, CA 92130, USA

2 Vesna Consulting, LLC, Irvine, CA, USA

\section{Introduction}

Swallowing difficulties (i.e., dysphagia) commonly occur in the general population, with up to $40 \%$ of adults experiencing problems $[1,2]$ and an increased incidence among the elderly [3, 4]. Among those requiring daily medications for chronic conditions, dysphagia may be especially critical because of difficulty swallowing oral dosage forms $[1,2,5-7]$. Studies show that the majority of individuals with dysphagia have difficulty taking oral medications [7]. Among community dwellers, $60 \%$ reported trouble swallowing pills; $68 \%$ opened a capsule or crushed a tablet because of swallowing difficulties, and $69 \%$ admitted missing at least one dose because of swallowing difficulties [8]. Those with chronic conditions, including Parkinson's disease, stroke, Alzheimer's disease, dementia, and other neurodegenerative conditions, are at especially high risk [3, 9-12]. Upwards of $80 \%$ of patients with Parkinson's disease experience difficulty swallowing solid oral dosage forms $[13,14]$.

Dosage form modification is common among those with swallowing difficulties [5]. Healthcare professionals often choose to empty the contents of the medication capsules 
into water, applesauce, or another vehicle to administer the dose to those with swallowing difficulties in the absence of supportive information. However, before altering a dosage form for administration, it is important to determine any effects on drug stability or recovery using standard methodology to determine the in vitro stability and recovery of altered solid oral dosage forms [15]. For those who have difficulty swallowing solid oral doses, simply crushing a tablet or emptying a capsule into a delivery vehicle such as water or applesauce is not recommended without data to confirm stability of the drug in the vehicle [7, 16-18]. Altering the original formulation may affect the absorption, stability, and delivery of the drug and markedly alter its pharmacological effect $[10,17,19,20]$.

The US Food and Drug Administration recently issued a draft guidance for assessing stability of drugs in liquid and soft food matrices [21]. The draft guidance includes methodology to assess vehicle impact on product quality attributes. Pimavanserin is the active moiety of pimavanserin tartrate, it is freely soluble in water [21]. Pimavanserin is currently commercially available as $34-\mathrm{mg}$ capsules and 10 -mg tablets. The bioavailability of the pimavanserin oral tablet or capsule and pimavanserin solution is essentially identical [22] and can be taken orally with or without food [21]. Pimavanserin is approved as a capsule containing 34 $\mathrm{mg}$ of the active drug for the treatment of hallucinations and delusions in patients with Parkinson's disease psychosis. The population with Parkinson's disease psychosis typically is older and may be especially at risk for dysphagia, which could affect proper administration of pimavanserin [13, 14]. In vitro studies were undertaken to evaluate the stability of pimavanserin, in different liquid/soft food vehicles and in water. These data provide in use stability information with different liquid/soft food vehicles.

\section{Methods}

\subsection{Chromatographic Procedure}

The following chromatographic procedure was used for testing samples in stability (Table 1). The method was verified for being suitable for testing pimavanserin in the several vehicles. Table 2 provides a summary of the elements of validation performed.

\subsection{Stability Study}

The stability of pimavanserin intended for oral administration was assessed by sprinkling the contents of one pimavanserin 34-mg capsule into water $(40 \mathrm{~mL})$, applesauce $(40 \mathrm{~g})$, vanilla Ensure ${ }^{\circledR}(60 \mathrm{~mL})$, or non-pulp orange juice $(60 \mathrm{~mL})$.
Samples were tested at time $0,2,4$, and $24 \mathrm{~h}$ after storage at ambient conditions.

Samples for assessment of assay (potency) stability of pimavanserin in vehicles were prepared as follows. Except for at time 0 , samples were prepared for each subsequent time sampling in triplicate for each vehicle. The average ( $n$ =6) accuracy/recovery results from the assay method verification were used as time 0 . For each sample, one capsule was weighed. The content of the capsule was dropped into a 500-mL volumetric flask containing the vehicle, and the empty capsule shell was weighed and discarded. The flasks were gently swirled to ensure the capsule contents were visually incorporated within the vehicle. The flasks were kept on the bench at an ambient temperature for up to $24 \mathrm{~h}$.

At the specified timepoint, approximately $450 \mathrm{~mL}$ of diluent (absolute ethanol) was added to the flask, and a stir bar was dropped into the flask. The samples were stirred vigorously for $2 \mathrm{~h}$, and the flasks were left on the bench overnight. The next day, the flasks were sonicated for approximately 15-30 min. The stir bar was removed and rinsed carefully with diluent into the flask. The flask was diluted to volume with diluent and mixed well by inversion.

Samples for assessment of degradation products stability of pimavanserin in vehicles were prepared as follows. Four samples $(n=4)$ were prepared for each vehicle. For each sample, one capsule was weighed. The content of the capsule was dropped into a $50-\mathrm{mL}$ volumetric flask, and the empty capsule shell was weighed and discarded. Five milliliters of each vehicle was added. The flasks were gently swirled to ensure the capsule contents were visually incorporated with the vehicle. The flasks remained on the bench at an ambient temperature for 2,4 , and $24 \mathrm{~h}$, and time 0 samples were processed immediately. At the specified timepoint, approximately $45 \mathrm{~mL}$ of diluent was added to the flask, and a stir bar was dropped into the flask. The solution was stirred vigorously for $2 \mathrm{~h}$, and the flask was left on the bench overnight. The next day the flasks were sonicated for approximately $30 \mathrm{~min}$. The stir bar was removed and rinsed carefully with diluent into the flask, and the flask was diluted to volume with diluent and mixed well by inversion. The assay solutions were prepared by diluting the impurity solutions 1:10 with diluent.

\section{Results}

\subsection{Stability Study}

The stability study demonstrated the ability to deliver $34 \mathrm{mg}$ of pimavanserin with $>95 \%$ recovery within $24 \mathrm{~h}$ after the contents of one pimavanserin 34-mg capsule were dispersed 


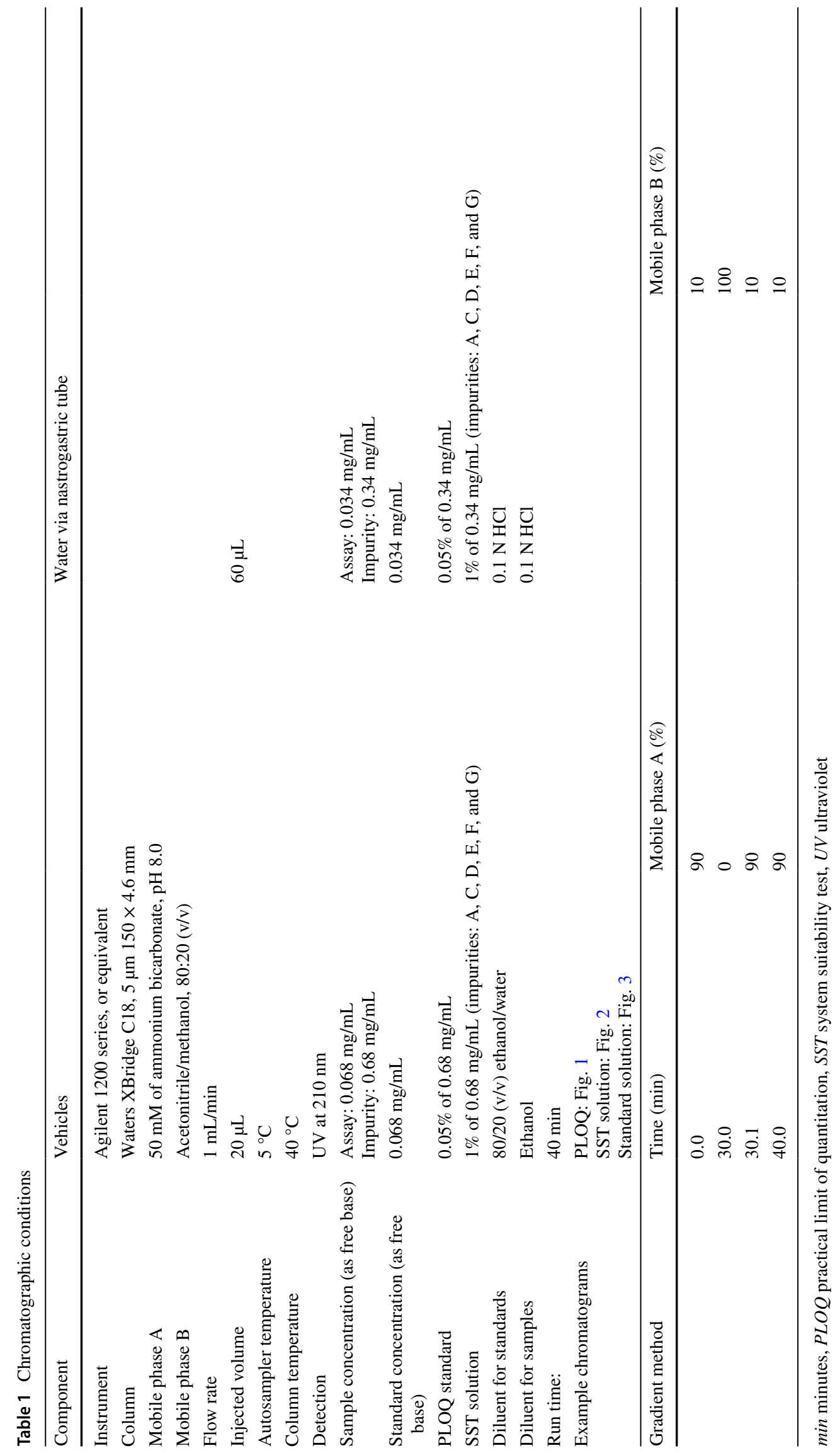




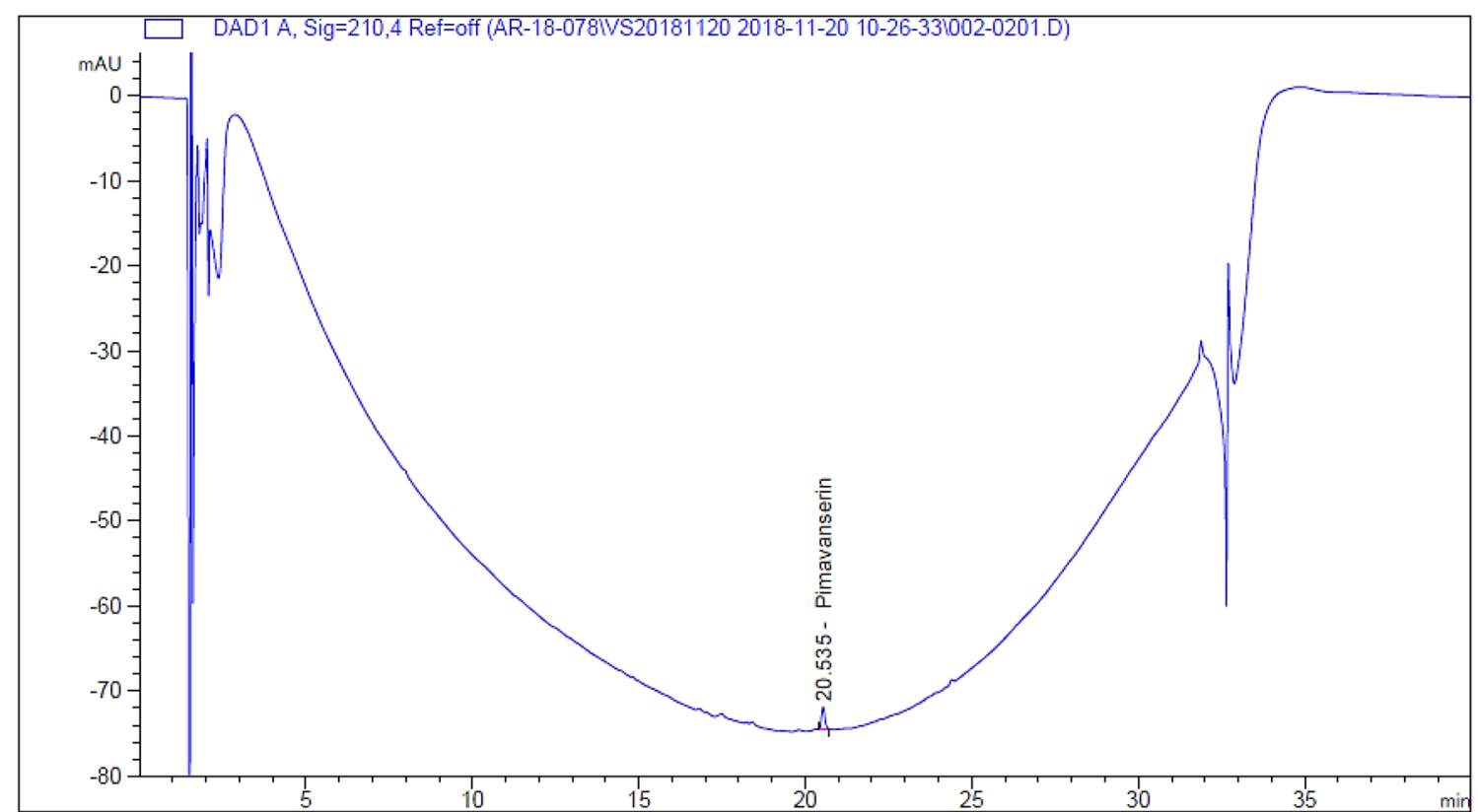

Fig. 1 Example chromatogram of the practical limit of quantitation at $0.05 \%$

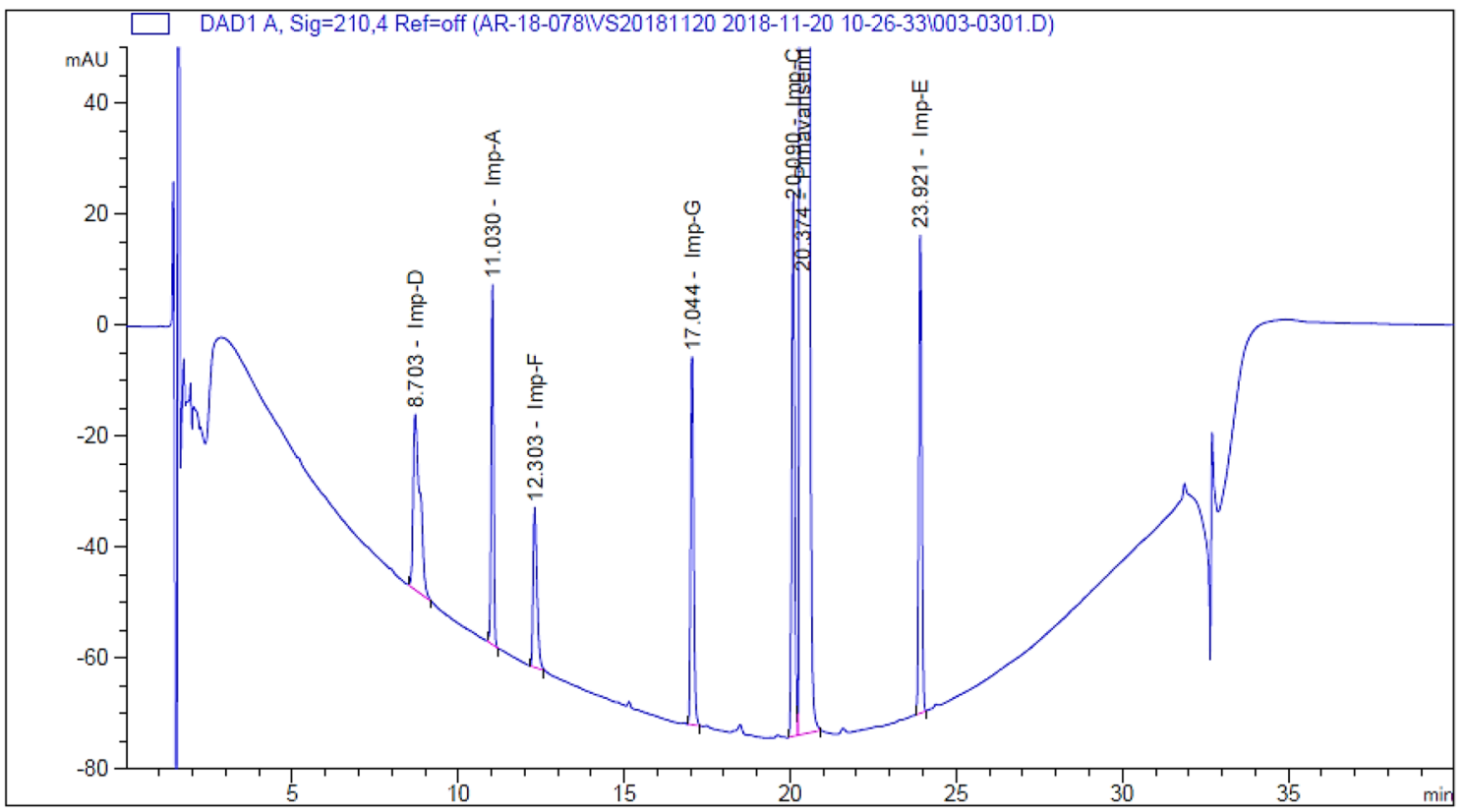

Fig. 2 System suitability test solution

in each of the vehicles, water, applesauce, vanilla Ensure, or orange juice (Table 3). Assay values up to $24 \mathrm{~h}$ for individual capsules were within $5 \%$ of time 0 , and no relevant change in the impurity profile was observed in any vehicle except for apple sauce. An assay value of $96.3 \%$ was observed for applesauce after $24 \mathrm{~h}$ of storage, which differed from time $0(101.9 \%)$ by $5.6 \%$.
Stability results for pimavanserin degradation products recovered from various food vehicles for individual and total degradation products were consistent between all timepoints for each vehicle (Table 4). Two peaks related to vanilla Ensure were observed in the samples extracted at time 0 and did not change significantly during stability storage. All assay results were within 5\% from time 0 


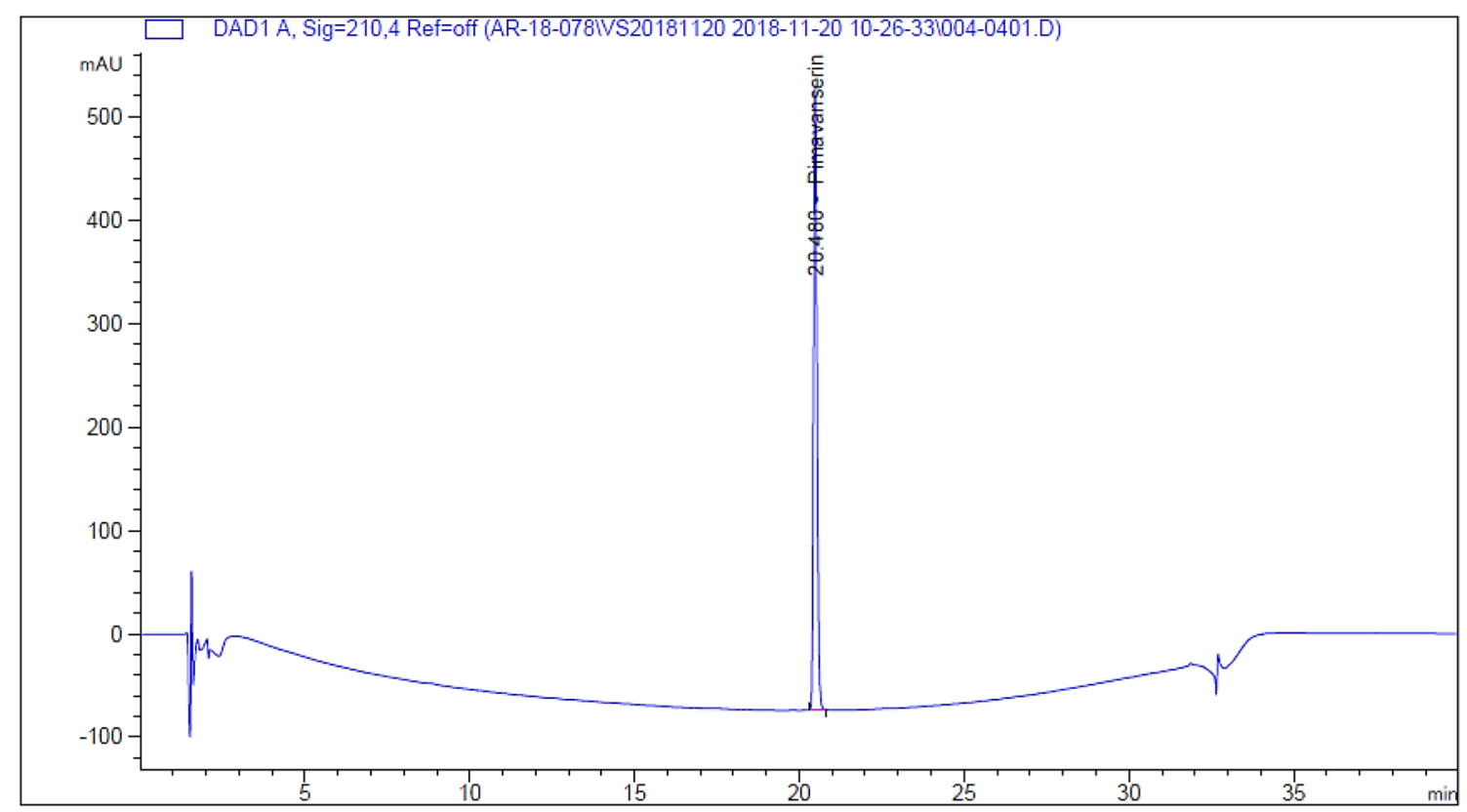

Fig. 3 Standard solution at $0.034 \mathrm{mg} / \mathrm{mL}$

Table 2 Results summary for assay

\begin{tabular}{|c|c|c|c|c|c|}
\hline Performance character- & Evaluated parameters & Target acceptance criteria & Results & & \\
\hline System precision & $\%$ RSD of peak areas and & NMT $1.0 \%$ & & $\mathrm{RT}(\min )$ & Area \\
\hline & $\begin{array}{l}\text { retention time from six } \\
\text { injections of a standard } \\
\text { preparation }(0.068 \mathrm{mg} / \\
\mathrm{mL})\end{array}$ & & $\% \mathrm{RSD}$ & 0.0 & 0.2 \\
\hline Actual capsules & For 34-mg capsules in & For each food vehicle: & Sample & Mean recovery $(\%)$ & $\operatorname{RSD}(\%)$ \\
\hline Accuracy/recovery at & each food vehicle: & mean \% recovery $(n=6)$ & Water & 98.9 & 4.5 \\
\hline $100 \%$ level $N=6$ for & mean recovery $(n=6)$ & \% recovery: $95-105 \%$ & Apple sauce & 101.9 & 1.3 \\
\hline & claim & & Orange juice & 100.3 & 1.2 \\
\hline & & & Vanilla ensure & 100.0 & 1.7 \\
\hline Precision & $\begin{array}{l}\text { RSD between assay values } \\
\text { obtained from six inde- } \\
\text { pendent sample prepara- } \\
\text { tions ( } n=6 \text {, one capsule } \\
\text { in each food vehicle, } \\
\text { testing only assay) }\end{array}$ & $\operatorname{RSD}(n=6)$ NMT $3 \%$ & See results in accuracy & & \\
\hline Linearity for vehicles: & (1) Coefficient of determi- & (1) NLT 0.998 & (1) $R^{2}=1.000$ & & \\
\hline $0.048-0.093 \mathrm{mg} / \mathrm{mL}$ & nation $\left(R^{2}\right)$ & (2) Record value & (2) Slope: 42,619 & & \\
\hline $\begin{array}{l}\text { (70-130\% of nominal con- } \\
\text { centration } 0.068 \mathrm{mg} / \mathrm{mL} \\
\text { in } 80: 20 \text { alcohol/water) }\end{array}$ & $\begin{array}{l}\text { (2) Slope } \\
\text { (3) Intercept }\end{array}$ & (3) Record value & (3) Intercept: 75 & & \\
\hline Linearity for water: & (1) Coefficient of determi- & (1) NLT 0.998 & (1) $R^{2}=0.9996$ & & \\
\hline $0.045-0.00018 \mathrm{mg} / \mathrm{mL}$ & nation $\left(R^{2}\right)$ & (2) Record value & (2) Slope: 129898 & & \\
\hline $\begin{array}{l}\text { (PLOQ: } 130 \% \text { of nomi- } \\
\text { nal concentration } 0.034 \\
\mathrm{mg} / \mathrm{mL} \text { in } 0.1 \mathrm{~N} \mathrm{HCl} \text { ) }\end{array}$ & $\begin{array}{l}\text { (2) Slope } \\
\text { (3) Intercept }\end{array}$ & (3) Record value & (3) Intercept: 5.67 & & \\
\hline Specificity & $\begin{array}{l}\text { (1) Each food vehicle } \\
\text { (2) Sample diluent }\end{array}$ & $\begin{array}{l}(1,2) \text { No significant inter- } \\
\text { ference }\end{array}$ & $\begin{array}{l}\text { (1) See Figs. 4, 5, } 6 \text { and } 7 \\
\text { (2) See Fig. } 8\end{array}$ & & \\
\hline
\end{tabular}

$N L T$ not less than, $N M T$ not more than, $P L O Q$ practical limit of quantitation, $R S D$ relative standard deviation, $R T$ retention time 


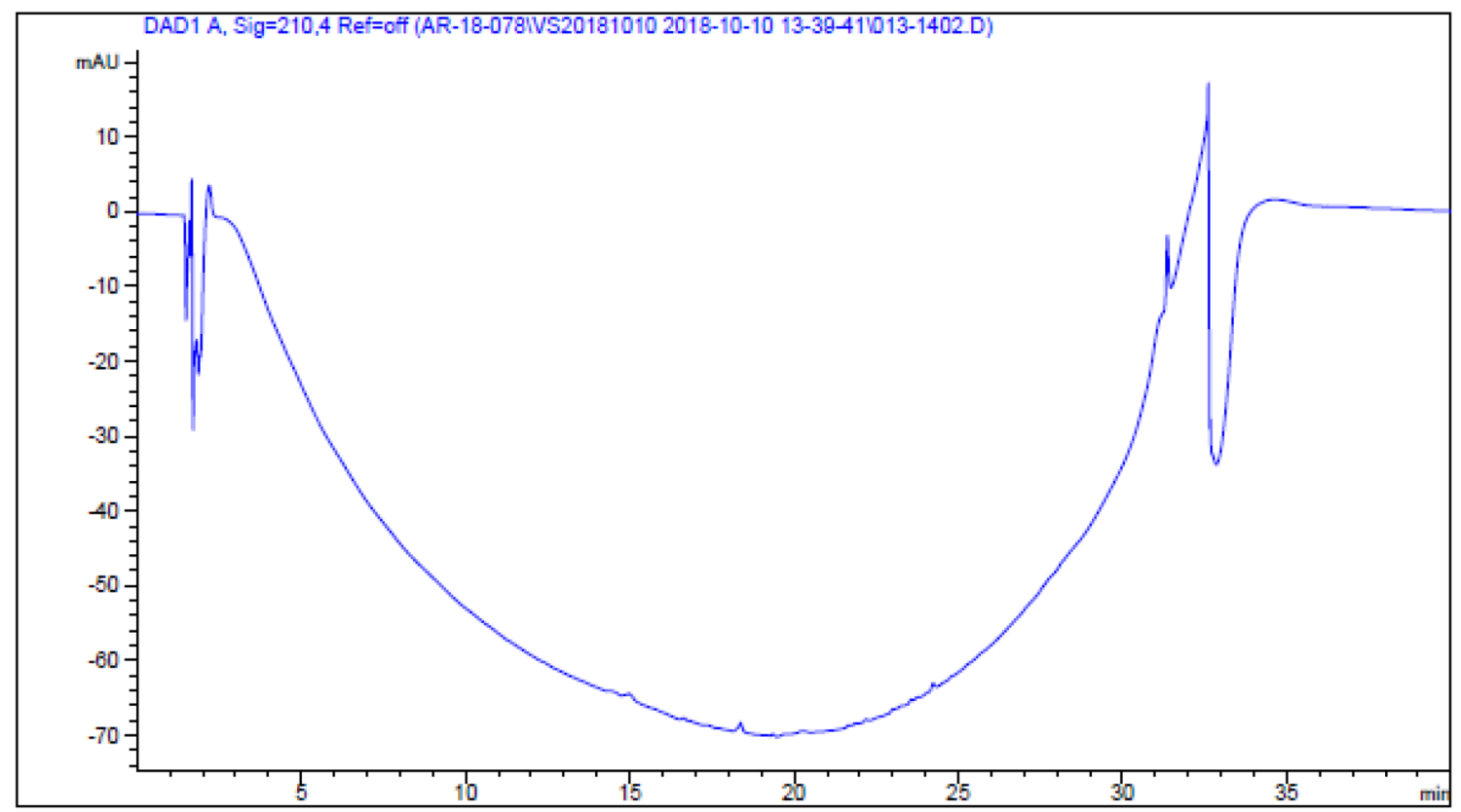

Fig. 4 Specificity: water assay blank

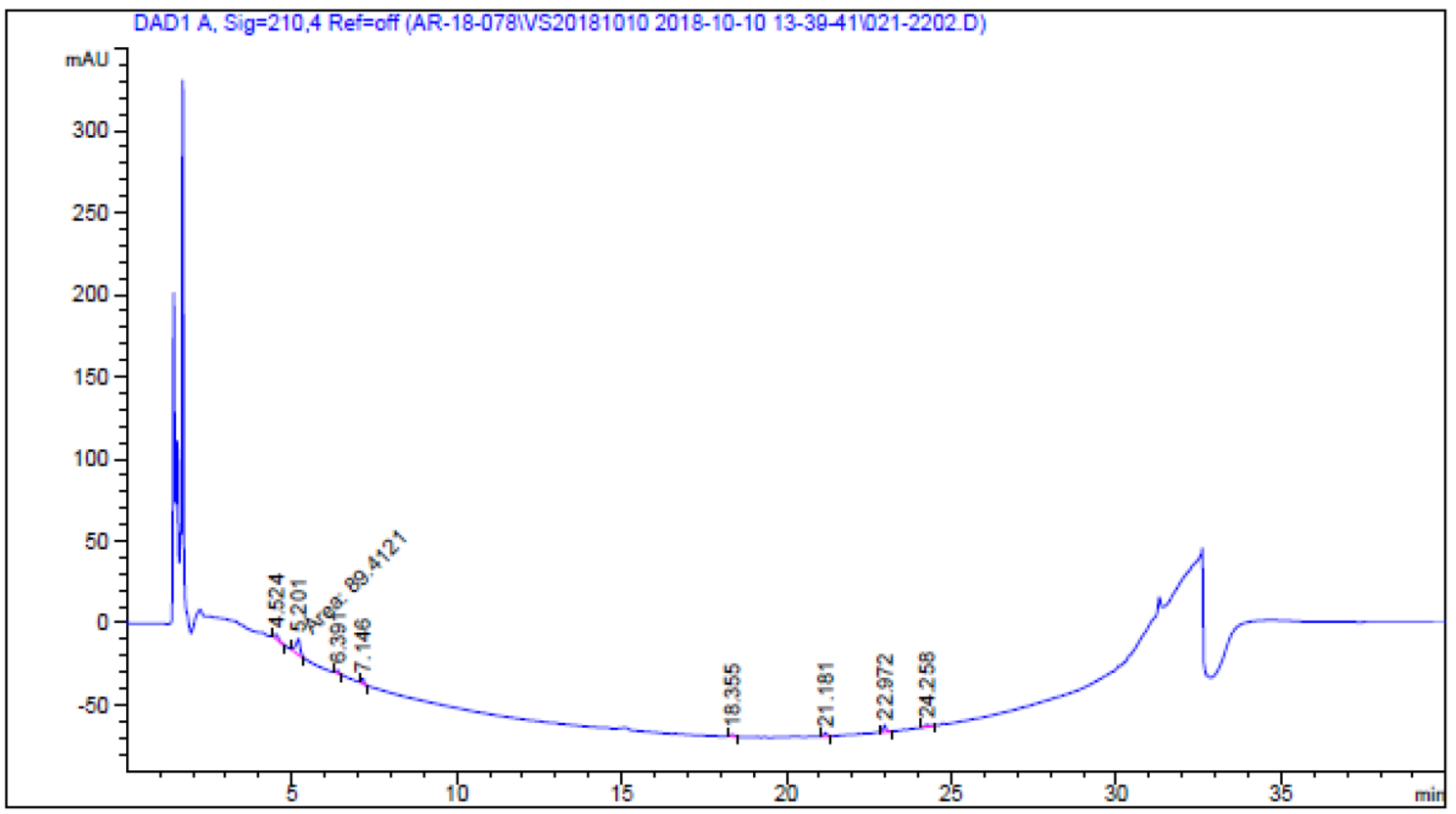

Fig. 5 Specificity: applesauce assay blank

and demonstrated an ability to deliver the expected dose (> 95\% recovery) within $24 \mathrm{~h}$ at ambient room temperature after being dispersed in water, applesauce, vanilla Ensure, or orange juice (Table 5).

\section{Discussion}

Very low levels of unknown impurities $(<0.1 \%)$ were found in either the stability or recovery portions of the studies conducted here. The stability of pimavanserin in all vehicles was acceptable over $24 \mathrm{~h}$ at ambient room temperature. 


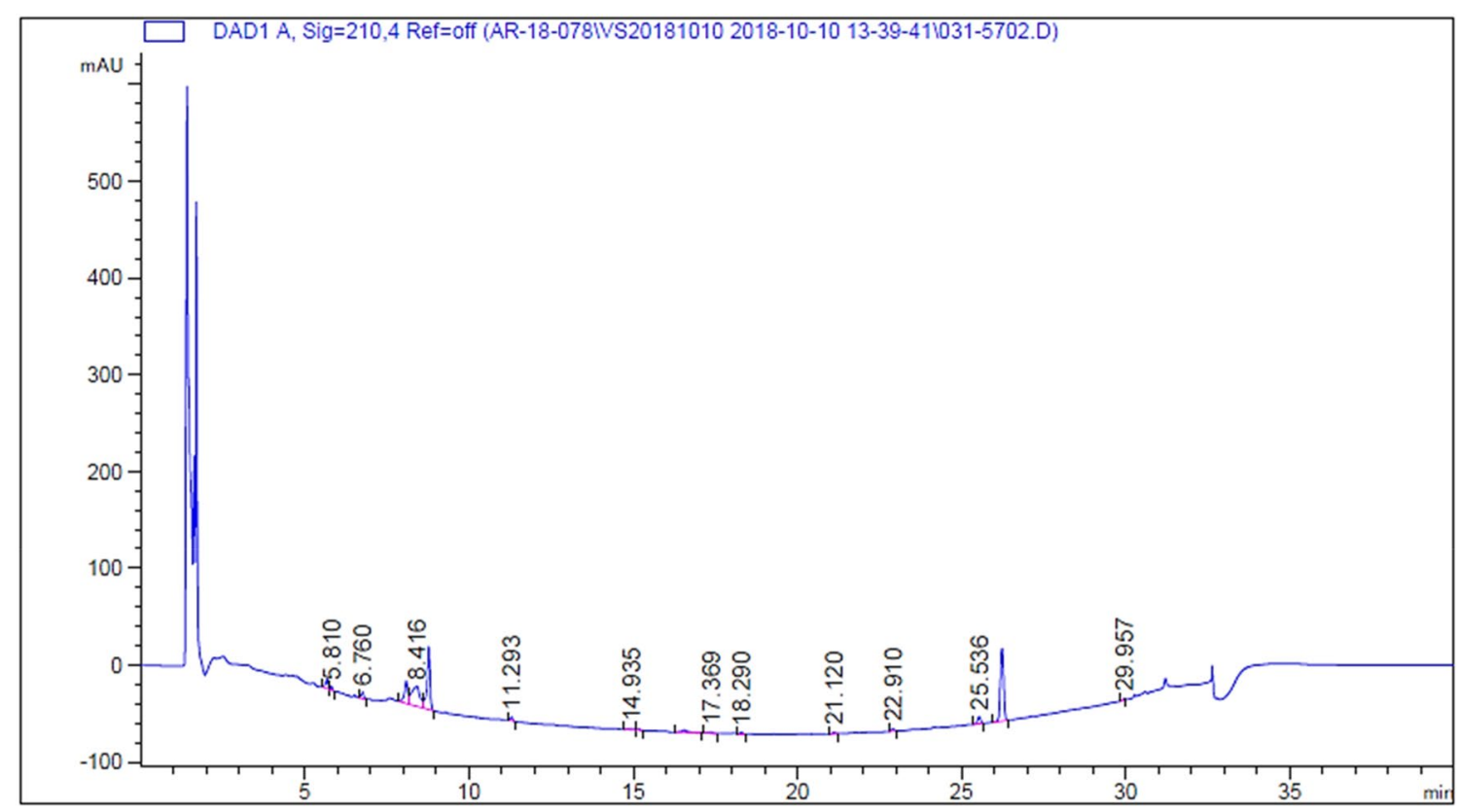

Fig. 6 Specificity: orange juice assay blank

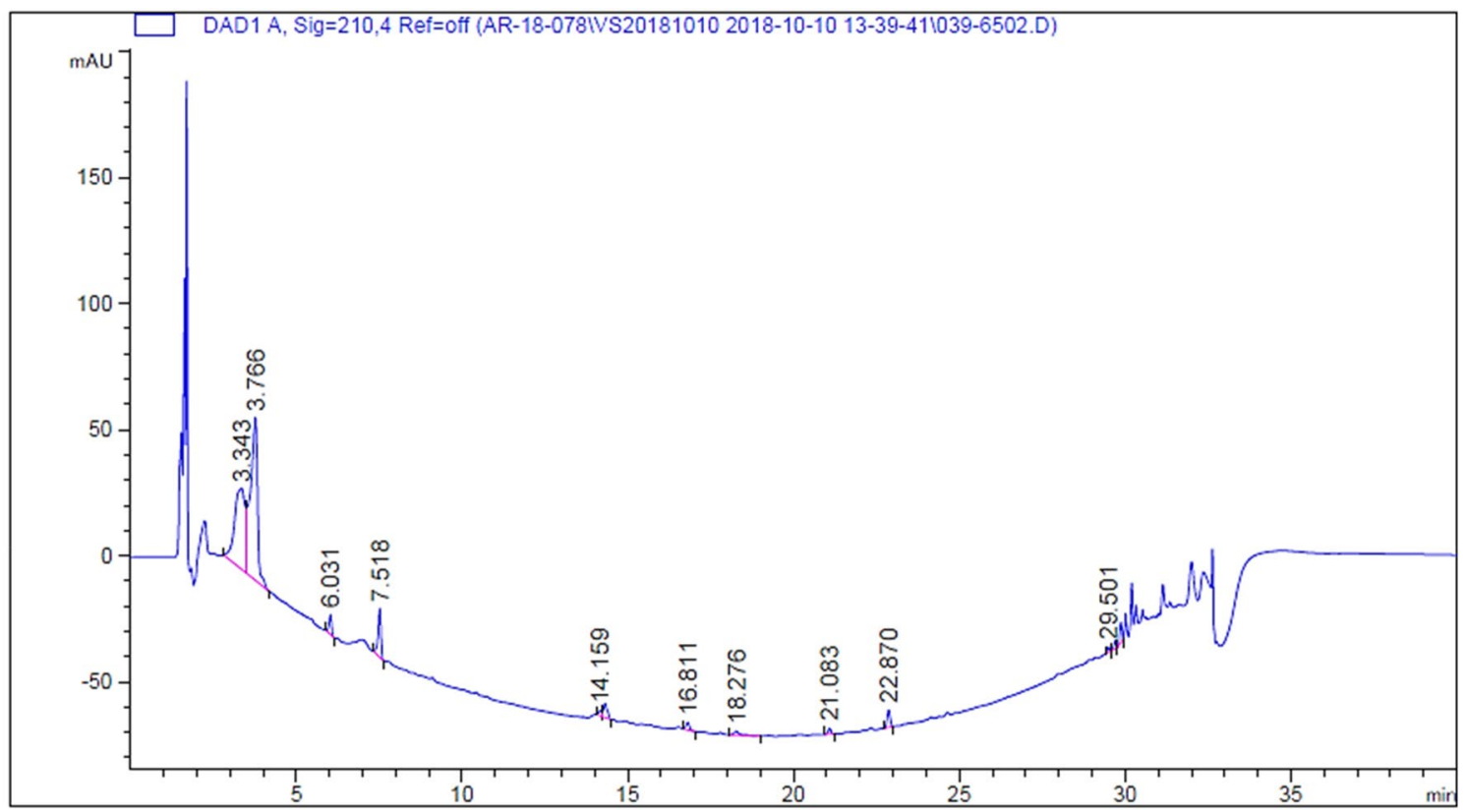

Fig. 7 Specificity: Ensure ${ }^{\circledR}$ assay blank

The consequences of crushing tablets or opening capsules for oral administration when not investigated for this method of administration can be serious for the patients. When the route of administration for a medication is changed, the pharmacokinetic properties can alter, specifically absorption, which could result in higher or lower systemic exposure and may render the treatment less well tolerated or less effective [7,23]. The active ingredient released may 


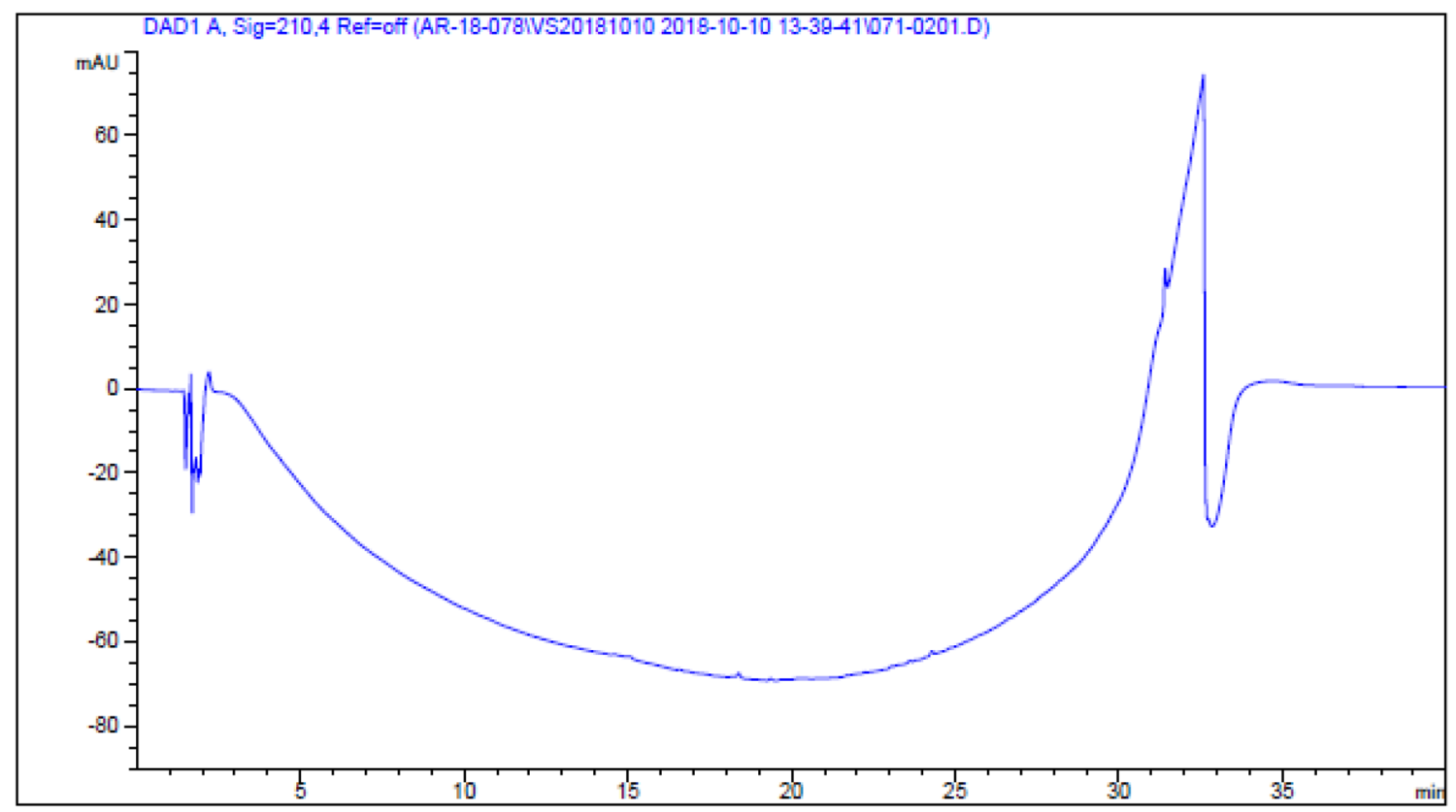

Fig. 8 Specificity: sample diluent ethanol

Table 3 In-use stability of pimavanserin from 34-mg capsules: assay study

\begin{tabular}{llcll}
\hline Sample/time & Amount of vehicle & Assay $(\%)(n=3)$ & $\begin{array}{l}\text { Assay at time } \\
0(\%)[n=6]\end{array}$ & $\begin{array}{l}\text { Absolute differ- } \\
\text { ence from time } \\
0(\%)\end{array}$ \\
\hline Water assay $T=2 \mathrm{~h}$ & \multirow{2}{*}{$40 \mathrm{~mL}$} & 97.7 & 98.9 & 1.2 \\
Water assay $T=4 \mathrm{~h}$ & & 95.6 & 3.3 \\
Water assay $T=24 \mathrm{~h}$ & & 99.3 & \multirow{2}{*}{101.9} & 0.4 \\
Applesauce assay $T=2 \mathrm{~h}$ & \multirow{2}{*}{$40 \mathrm{~g}$} & 99.9 & & 2.0 \\
Applesauce assay $T=4 \mathrm{~h}$ & & 97.7 & 4.2 \\
Applesauce assay $T=24 \mathrm{~h}$ & & 96.3 & 5.6 \\
Orange juice assay $T=2 \mathrm{~h}$ & $60 \mathrm{~mL}$ & 99.2 & 100.3 & 1.1 \\
Orange juice assay $T=4 \mathrm{~h}$ & & 98.0 & & 2.3 \\
Orange juice assay $T=24 \mathrm{~h}$ & & 98.3 & 100.0 & 2.0 \\
Ensure assay $T=2 \mathrm{~h}$ & $60 \mathrm{~mL}$ & 100.3 & 0.3 \\
Ensure assay $T=4 \mathrm{~h}$ & & 100.7 & 0.7 \\
Ensure assay $T=24 \mathrm{~h}$ & & 98.1 & 1.9 \\
\hline
\end{tabular}

$h$ hours, $T$ time degrade on contact with light, moisture, or the vehicle used for administration [7].

The target patient population for pimavanserin, patients with Parkinson's disease psychosis, are typically older and have dysphagia as a consequence of Parkinson's disease, which often impacts swallowing solid oral dosage forms $[13,14]$. This population of older patients with dysphagia most often have one or more chronic diseases in addition to Parkinson's disease and are taking multiple medications. Based on these results, pimavanserin capsule contents can be emptied and mixed into water, applesauce, orange juice, or vanilla Ensure without impacting the stability of the product. 
Table 4 In-use stability for pimavanserin degradation products and impurities

\begin{tabular}{|c|c|c|c|c|c|c|c|}
\hline Sample & Run time (min) & RRT & Impurity & $\begin{array}{l}T=0 \% \mathrm{w} / \mathrm{w} \\
n=3\end{array}$ & $\begin{array}{l}T=2 \mathrm{~h} \% \mathrm{w} / \mathrm{w} \\
n=3\end{array}$ & $\begin{array}{l}T=4 \mathrm{~h} \% \mathrm{w} / \mathrm{w} \\
n=3\end{array}$ & $\begin{array}{l}T=24 \mathrm{~h} \\
\% \mathrm{w} / \mathrm{w} \\
n=3\end{array}$ \\
\hline \multirow[t]{3}{*}{ Water } & 8.98 & 0.44 & Pimavanserin related peak 1 & 0.23 & 0.24 & 0.23 & 0.25 \\
\hline & 20.06 & 0.99 & Unspecified RRT 0.99 & 0.10 & 0.10 & 0.10 & 0.10 \\
\hline & & & Total & 0.33 & 0.34 & 0.33 & 0.35 \\
\hline \multirow[t]{3}{*}{ Applesauce } & 8.91 & 0.44 & Pimavanserin Related peak 1 & 0.19 & 0.21 & 0.22 & 0.22 \\
\hline & 19.95 & 0.99 & Unspecified RRT 0.99 & 0.09 & 0.10 & 0.10 & 0.09 \\
\hline & & & Total & 0.28 & 0.31 & 0.32 & 0.31 \\
\hline \multirow[t]{3}{*}{ Orange juice } & 8.92 & 0.44 & Pimavanserin related peak 1 & 0.17 & 0.17 & 0.17 & 0.17 \\
\hline & 20.07 & 0.99 & Unspecified RRT 0.99 & 0.09 & 0.09 & 0.09 & 0.09 \\
\hline & & & Total & 0.26 & 0.26 & 0.26 & 0.26 \\
\hline \multirow[t]{5}{*}{ Ensure } & 8.95 & 0.44 & Pimavanserin related peak 1 & 0.22 & 0.20 & 0.23 & 0.23 \\
\hline & 18.31 & 0.90 & Ensure related peak & 0.08 & 0.08 & 0.08 & 0.07 \\
\hline & 20.06 & 0.99 & Unspecified RRT 0.99 & 0.09 & 0.10 & 0.09 & 0.10 \\
\hline & 22.29 & 1.10 & Ensure related peak & 0.06 & 0.05 & 0.06 & 0.06 \\
\hline & & & Total & 0.45 & 0.43 & 0.46 & 0.46 \\
\hline
\end{tabular}

$h$ hours, $\min$ minutes, $R R T$ relative retention time, $T$ time

Table 5 In-use stability for pimavanserin: assay results from impurity samples study

\begin{tabular}{lllll}
\hline Sample/time & $\begin{array}{l}\text { Amount of } \\
\text { vehicle }\end{array}$ & Assay (\%) & Time 0 (\%) & $\begin{array}{l}\text { Absolute differ- } \\
\text { ence from time } \\
0(\%)\end{array}$ \\
\hline Water assay $T=0$ & $5 \mathrm{~mL}$ & 95.6 & 98.9 & 3.3 \\
Water assay $T=2 \mathrm{~h}$ & & 98.2 & & 0.7 \\
Water assay $T=4 \mathrm{~h}$ & 97.1 & & 1.8 \\
Water assay $T=24 \mathrm{~h}$ & & 97.5 & & 1.4 \\
Applesauce assay $T=0$ & $5 \mathrm{~g}$ & 97.5 & 101.9 & 4.4 \\
Applesauce assay $T=2 \mathrm{~h}$ & & 99.4 & & 2.5 \\
Applesauce assay $T=4 \mathrm{~h}$ & & 104.1 & 2.2 \\
Applesauce assay $T=24 \mathrm{~h}$ & & 99.5 & & 2.4 \\
Orange juice assay $T=0$ & $5 \mathrm{~mL}$ & 97.7 & 100.3 & 2.6 \\
Orange juice assay $T=2 \mathrm{~h}$ & & 97.5 & & 2.8 \\
Orange juice assay $T=4 \mathrm{~h}$ & & 96.4 & & 3.9 \\
Orange juice assay $T=24 \mathrm{~h}$ & & 99.2 & & 1.1 \\
Ensure assay $T=0$ & $5 \mathrm{~mL}$ & 97.1 & 100.0 & 2.9 \\
Ensure assay $T=2 \mathrm{~h}$ & & 94.6 & & 5.4 \\
Ensure assay $T=4 \mathrm{~h}$ & & 97.9 & & 2.1 \\
Ensure assay $T=24 \mathrm{~h}$ & & 97.3 & & 2.7 \\
\hline
\end{tabular}

$h$ hours, $T$ time

\section{Conclusions}

Based on sufficient recovery and minimal degradation products observed for pimavanserin when mixed into vehicles and tested for up to $24 \mathrm{~h}$, it can be concluded that:
- Pimavanserin can be administered by emptying the capsule contents into applesauce, orange juice, vanilla Ensure, or water and delivering orally.

- Pimavanserin offers the flexibility to be administered using alternative vehicles to accommodate patient needs. 
Acknowledgements The authors acknowledge the editorial assistance of Richard S. Perry, PharmD, in the preparation of this manuscript, which was supported by ACADIA Pharmaceuticals Inc., San Diego, CA, USA.

\section{Declarations}

Funding The work was funded by ACADIA Pharmaceuticals Inc., San Diego, CA, USA.

Conflict of interest $\mathrm{YA}, \mathrm{AB}$, and JN are employees of ACADIA Pharmaceuticals Inc., San Diego, CA, USA. VS provided consulting services under contract to ACADIA Pharmaceuticals, Inc.

Ethics approval The study included no human or animals and therefore this is not applicable.

Consent to Participate Not applicable.

Consent for Publication All authors approved submission of this manuscript.

Availability of Data and Material All relevant data are included in this manuscript.

Code Availability Not applicable.

Authors' Contributions AB: concept, design, conduct, analysis, interpretation, writing and approval of manuscript. YA: concept, design, conduct, analysis, interpretation, writing and approval of manuscript. VS: analysis, interpretation, and review and approval of manuscript. JN: review and approval of manuscript for submission.

Open Access This article is licensed under a Creative Commons Attribution-NonCommercial 4.0 International License, which permits any non-commercial use, sharing, adaptation, distribution and reproduction in any medium or format, as long as you give appropriate credit to the original author(s) and the source, provide a link to the Creative Commons licence, and indicate if changes were made. The images or other third party material in this article are included in the article's Creative Commons licence, unless indicated otherwise in a credit line to the material. If material is not included in the article's Creative Commons licence and your intended use is not permitted by statutory regulation or exceeds the permitted use, you will need to obtain permission directly from the copyright holder. To view a copy of this licence, visit http://creativecommons.org/licenses/by-nc/4.0/.

\section{References}

1. Fields J, Go JT, Schulze KS. Pill properties that cause dysphagia and treatment failure. Curr Ther Res Clin Exp. 2015;77:79-82.

2. Schiele JT, Quinzler R, Klimm HD, Pruszydlo MG, Haefeli WE. Difficulties swallowing solid oral dosage forms in a general practice population: prevalence, causes, and relationship to dosage forms. Eur J Clin Pharmacol. 2013;69:937-48.

3. Stegemann S, Gosch M, Breitkreutz J. Swallowing dysfunction and dysphagia is unrecognized challenge for oral therapy. Int $\mathrm{J}$ Pharm. 2012;430:197-206.
4. Fusco S, Cariati D, Schepisi R, et al. Management of oral drug therapy in elderly patients with dysphagia. J Gerontol Geriatr. 2016;64:9-20.

5. Forough AS, Lau ET, Steadman KJ, et al. A spoonful of sugar helps the medicine go down? A review of strategies for making pills easier to swallow. Patient Prefer Adher. 2018;12:1337-46.

6. Marquis J, Schneider MP, Payot V, et al. Swallowing difficulties with oral drugs among polypharmacy patients attending community pharmacies. Int J Clin Pharm. 2013;35:1130-6.

7. Taylor S, Glass BD. Altering dosage forms for older adults. Aust Prescr. 2018;41:191-3.

8. Strachan I, Greener M. Medication-related swallowing difficulties may be more common than we realise. Pharm Pract. 2005; 15:411-4.

9. Buhmann C, Bihler M, Emich K, et al. Pill swallowing in Parkinson's disease: a prospective study based on flexible endoscopic evaluation of swallowing. Parkinsonism Relat Disord. 2019;62:51-6.

10. Lau ETL, Steadman KJ, Cichero JAY, Nissen LM. Dosage form modification and oral drug delivery in older people. Adv Drug Deliv Rev. 2018;135:75-84.

11. Sestili M, Logrippo S, Cespi M, et al. Potentially inappropriate prescribing of oral solid medications in elderly dysphagic patients. Pharmaceutics. 2018;10(4):E280. https://doi.org/10.3390/pharm aceutics 10040280 .

12. Takizawa C, Gemmell E, Kenworthy J, Speyer R. A systematic review of the prevalence of oropharyngeal dysphagia in stroke, Parkinson's disease, Alzheimer's disease, head injury, and pneumonia. Dysphagia. 2016;31:434-41.

13. Pflug $\mathrm{C}$, Bihler M, Emich $\mathrm{K}$, et al. Critical dysphagia is common in Parkinson disease and occurs even in early stages: a prospective cohort study. Dysphagia. 2018;33:41-50.

14. Kalf JG, de Swart BJ, Bloem BR, Munneke M. Prevalence of oropharyngeal dysphagia in Parkinson's disease: a meta-analysis. Parkinsonism Relat Disord. 2012;18:311-5.

15. Ren $\mathrm{P}, \mathrm{Cui} \mathrm{M}$, Anand $\mathrm{O}$, et al. In vitro approaches to support bioequivalence and substitutability of generic proton pump inhibitors via nasogastric tube administration. AAPS J. 2017;19:1593-9.

16. Cornish P. "Avoid the crush": hazards of medication administration in patients with dysphagia or a feeding tube. CMAJ. 2005; 172(7):871-2.

17. Logrippo S, Ricci G, Sestili M, et al. Oral drug therapy in elderly with dysphagia: between a rock and a hard place! Clin Interv Aging. 2017;12:241-51.

18. Masilamoney M, Dowse R. Knowledge and practice of healthcare professionals relating to oral medicine use in swallowing-impaired patients: a scoping review. Int J Pharm Pract. 2018;26:199-209.

19. Williams NT. Medication administration through enteral feeding tubes. Am J Health Syst Pharm. 2008;65:2347-57.

20. Carnaby-Mann G, Michael CM. Pill swallowing by adults with dysphagia. Arch Otolaryngol Head Neck Surg. 2005;131:970-5.

21. US FDA. Use of liquids and/or soft foods as vehicles for drug administration: general considerations for selection and in vitro methods for product quality assessments. July 2018. https://www. fda.gov/Drugs/GuidanceComplianceRegulatoryInformation/ Guidances/default.htm or https://www.regulations.gov.

22. NUPLAZID ${ }^{\circledR}$ package insert. San Diego (CA): ACADIA Pharmaceuticals, Inc., 2019.

23. Undre N, Dickinson J. Relative bioavailability of single doses of prolonged-release tacrolimus administered as a suspension, orally or via a nasogastric tube, compared with intact capsules: a phase 1 study in healthy participants. BMJ Open. 2017;7:e012252. 